\title{
Contemporary management and outcome of myelomeningocele: the Rotterdam experience
}

\author{
Jochem K. H. Spoor, MD, ${ }^{1}$ Pravesh S. Gadjradj, MD,,2 Alex J. Eggink, MD, PhD, ${ }^{3}$ \\ Philip L. J. DeKoninck, MD, PhD, ${ }^{3}$ Bart Lutters, MD, ${ }^{1}$ Jeroen R. Scheepe, MD, PhD, ${ }^{4}$ \\ Jetty van Meeteren, MD, PhD, ${ }^{5}$ Peter C. J. de Laat, MD, PhD, ${ }^{6}$ Marie Lise van Veelen, MD, PhD, ${ }^{1}$ \\ and Tjeerd H. R. de Jong, MD 1
}

\begin{abstract}
${ }^{1}$ Department of Neurosurgery; ${ }^{3}$ Department of Obstetrics and Gynaecology, Division of Obstetrics and Fetal Medicine; ${ }^{4}$ Department of Urology; ${ }^{5}$ Rijndam Rehabilitation; and ${ }^{6}$ Department of Pediatrics, Erasmus MC University Medical Center Rotterdam; and 'Department of Neurosurgery, Leiden University Medical Center, Leiden, The Netherlands
\end{abstract}

OBJECTIVE Myelomeningocele (MMC) is the most common form of spina bifida, with a lifelong impact on the quality of life for infants born with this condition. In recent decades, fetal surgery has evolved from an experimental therapy to standard of care for many centers in the world. In this study, the authors aimed to provide an overview of the current management and outcomes for infants with MMC managed at their institution. This then provides a center-specific historical cohort for comparison with future antenatal-treated MMC cases.

METHODS This is a retrospective, single-institution cohort study including all consecutive MMC cases between January 1, 2000, and June 1, 2018, at Erasmus MC. Outcome data included closure of the defect (location, timing, and surgical parameters), hydrocephalus management, Chiari malformation type II (CMTII) management, incidence of spinal cord tethering and outcome, motor outcomes, and continence.

RESULTS A total of 93 patients were included with predominantly lumbosacral lesions. Two patients died during followup. Hydrocephalus was present in $84 \%$, with a $71 \%$ ventriculoperitoneal shunt reoperation rate. Surgery was performed in $12 \%$ for a tethered spinal cord at a mean age of 8 years. Decompression surgery was performed in 3 patients for CMTII. Special education in 63\% was significantly associated with hydrocephalus $(p<0.015)$. Nineteen percent of patients were able to walk independently, and $47 \%$ were nonambulators. Social continence for urine was obtained in $75 \%$ of patients, $4 \%$ had fecal incontinence.

CONCLUSIONS This study provides an overview of current MMC outcomes at the authors' center and will serve as a historical cohort for comparison with future fetal surgery cases operated on at the center in the coming years. Apart from a relatively low surgical untethering rate, the authors' outcome data are comparable to those in the literature. Hydrocephalus is highly prevalent in postnatally treated MMC patients; in this study as in much of the literature, hydrocephalus is correlated with a low cognitive function. Fetal surgery for MMC halves the need for shunt treatment in a select group of MMC pregnancies, constituting a major indication for us to undergo the transition to a fetal surgery center. The fetal benefits of open antenatal surgery for MMC are well established, yet long-term data on especially tethered spinal cord are eagerly awaited.

https://thejns.org/doi/abs/10.3171/2019.7.FOCUS19447

KEYWORDS spina bifida; myelomeningocele; tethering

$\mathrm{M}$ YELOMENINGOCELE (MMC) is the most common form of spina bifida. Patients with MMC face lifelong disabilities such as paralysis of the lower limbs; sensory loss; impaired cognition; and bladder, bowel, and sexual dysfunction. Most cases are identified during routine anomaly scanning around 20 weeks of ges- tation, and a large proportion of parents opt not to continue the pregnancy (termination of pregnancy). This, in combination with the increased use of folic acid supplementation during pregnancy, has reduced the incidence of neural tube defects in the past decades. ${ }^{31}$ For instance, in the US, the incidence of neural tube defects at birth decreased

ABBREVIATIONS CIC = clean intermittent catheterization; CMTII = Chiari malformation type II; ETV = endoscopic third ventriculostomy; MMC = myelomeningocele; MOMS = Management of Myelomeningocele Study; NSBPR = National Spina Bifida Patient Registry; TSC = tethered spinal cord; VP = ventriculoperitoneal.

SUBMITTED May 31, 2019. ACCEPTED July 31, 2019.

INCLUDE WHEN CITING DOI: 10.3171/2019.7.FOCUS19447. 
19\% following folic acid supplementation between 1990 and 1999.9,16 However, more recent data showed that this dramatic decline in incidence has stabilized in later years, with approximately 3.39 per 10,000 children born with spina bifida in 2003-2004. ${ }^{4}$

Management of MMC is complex, and multidisciplinary treatment is warranted. Usually, shortly after birth, the MMC defect will be closed surgically to prevent further damage to the spinal cord and infection. MMC patients are at risk for developing other conditions. A highly prevalent one is the development of hydrocephalus. ${ }^{14} \mathrm{Di}$ version of CSF is usually performed by shunting, alternatively by creating an endoscopic third ventriculostomy (ETV).

Another condition associated with MMC is Chiari malformation type II (CMTII). ${ }^{2,20,23,24}$ Even though almost all patients with postnatal MMC repair have a CMTII on imaging, only a proportion present with clinical symptoms. Clinical symptoms may include neck pain, muscle weakness, central apnea, dysphagia, stridor, and opisthotonus. The first-line treatment of CMTII is also ventriculoperitoneal (VP) shunting, whereas foramen magnum decompression with or without duraplasty can be considered when shunting is not providing adequate relief of symptoms.

In addition to CMTII, the majority of patients with MMC have a tethered spinal cord (TSC) on imaging, but only a minority will also present with clinical symptoms. Tethering of the spinal cord can result in back or leg pain, syringomyelia, decline in motor function, progression of scoliosis, and bladder dysfunction. The goal of surgical treatment is to release the spinal cord..$^{19}$

In 2011, the results of the Management of Myelomeningocele Study (MOMS) trial were published. ${ }^{1}$ In this randomized controlled trial, 183 women before 26 weeks of gestation were randomized between prenatal surgery and conventional postnatal repair. Despite the more frequent occurrence of pregnancy-related complications such as preterm birth, the outcomes of the patients who underwent antenatal repair were favorable. For example, less than half of them required the placement of a shunt. Furthermore, the patients had a reduced rate of CMTII and better cognitive function and motor skills. Although clinically relevant, tethering of the spinal cord is often a late-occurring complication, and long-term data are not available. Fetal closure of MMC seems to be associated with a higher TSC rate, even at a very young age as shown in the MOMS trial.

The purpose of the current study was to evaluate the contemporary management and long-term outcomes of patients with MMC managed at our institution, Sophia Children's Hospital, Rotterdam, the Netherlands. To this end, we assessed the rate of shunting, untethering procedures, and decompression interventions for CMTII in relation to clinical outcome. This series provides a contemporary cohort that could improve counseling parents about the long-term complications and risks of postnatal repair. This also allows comparison to much-awaited long-term outcomes of the MOMS trial, in particular to TSC rates. Furthermore, as our institution is currently transitioning toward the establishment of a fetal surgery center, the present study provides a center-specific historical cohort to compare with future antenatal-treated MMC cases.

\section{Methods}

\section{Management of MMC at the Sophia Children's Hospital}

Annually, approximately 15 patients are diagnosed with MMC at the Erasmus MC-Sophia Children's Hospital. The diagnosis is usually suspected at the routine 20 -week anomaly ultrasound scan and confirmed with a more detailed scan at our center. The latter also aims to diagnose associated abnormalities and to evaluate the extent of the spinal abnormality (i.e., lesion level, presence of CMTII, hydrocephalus). All women carrying an MMC fetus are counseled by a maternal fetal medicine specialist as well as a pediatric neurosurgeon. Amniocentesis is offered to identify associated genetic abnormalities. If the decision is made to continue the pregnancy, the ensuing pregnancy care takes place at our institution.

Postnatal closure consists of microsurgical freeing of the placode, followed by neurulation of the tube. Next, the dura is dissected and closed around the newly constructed neural tube. A musculofascial flap is used to cover the defect, and the skin is closed. In large skin defects, the plastic surgeon is asked to perform a skin flap.

If the parents opt for fetal surgery, they are currently referred to University Hospitals Leuven, Belgium. Further follow-up and delivery by cesarean section in the current and future pregnancies take place at our institution.

After birth, MMC patients are followed regularly at the MMC outpatient clinic. During these specific consulting visits, patients are seen by a multidisciplinary team of specialists from departments such as neurosurgery, orthopedic surgery, rehabilitation medicine, urology, pediatrics, neurology, social work, and furthermore by dedicated nurses.

\section{Patient Selection and Data Extraction}

This is a retrospective, single-institution cohort study. Using a departmental database, a chart review was performed on all patients born between January 1, 2000, and June 1, 2018, who underwent closure of an MMC defect. All surgically treated MMC patients who are currently under treatment at the Sophia Children's Hospital were included. Patients were excluded if they had any other form of spina bifida (such as spina bifida occulta).

The following outcome data were collected: 1) type of surgical closure of the MMC defect, location of defect, timing of repair, and surgical parameters; 2) management of hydrocephalus: shunt procedures, ETVs, and reoperations; 3) management of CMTII and an indication for decompression; 4) management of spinal cord untethering; and 5) long-term quality of life: bowel and bladder function, level of functioning, and the ability to walk according to the Hoffer classification. ${ }^{8}$

Institutional review board approval was not needed since this was an anonymous retrospective study.

\section{Statistical Analysis}

IBM SPSS (version 21.0, IBM Corp.) was used for analysis of data; $p<0.05$ was considered to be statistically sig- 
TABLE 1. Baseline characteristics of patients and surgical closure of the MMC

\begin{tabular}{lc}
\hline \multicolumn{2}{c}{ No. of Patients $(\%)$} \\
\hline Total & 93 \\
\hline Sex & $46(49.5)$ \\
\hline Male & $47(50.5)$ \\
\hline Female & \\
\hline Gestational age in wks $(\mathrm{n}=73)$ & $14(19.2)$ \\
\hline$<37$ wks & $59(80.8)$ \\
\hline$\geq 37$ wks & $17(21.3)$ \\
\hline Mean time of op after birth $(\mathrm{n}=80)$ & $63(78.8)$ \\
\hline$\leq 48$ hrs & $58(92.1)$ \\
\hline$\geq 48$ hrs & \\
\hline$\leq 7$ days & $5(5.4)$ \\
\hline Defect location $(n=93)$ & $13(14.0)$ \\
\hline Thoracic & $1(1.1)$ \\
\hline Thoracolumbar & $35(37.6)$ \\
\hline Thoracolumbosacral & $28(30.1)$ \\
\hline Lumbar & $11(11.8)$ \\
\hline Lumbosacral &
\end{tabular}

nificant. The $\mathrm{p}$ value and confidence intervals were both determined using the Pearson chi-square test. Categorical data are presented as valid percentages.

\section{Results}

\section{Patient Characteristics and Closure of the Defect}

A total of 93 patients were included in this study (47 females); 3 patients had been excluded because 2 of them had a meningocele and 1 had a spina bifida occulta. All patients were followed up for a mean duration of 11.8 years (range 1.0-18.2 years). No patients were lost to fol- low-up. No patients died after delivery or before surgical closure. Two patients died during follow-up, one due to an unrelated infection at the age of 10 months and the other at the age of 17 years who had a short history of deterioration, which ended in asystole. Although this patient had never shown any signs of a clinically relevant CMTII, the deterioration and subsequent death might at least be partly due to CMTII.

Fifty-nine $(80.8 \%, 59 / 73)$ patients were born after 37 weeks of gestation, while $14(19.2 \%, 14 / 73)$ were born between 33 and 37 weeks. Table 1 shows the level of the MMC lesions. Most were located in the lumbosacral area.

The two most recent patients underwent an antenatal repair abroad, while the remaining 91 underwent postnatal closure of the MMC. Postnatal repair was performed within 48 hours after birth in 17 patients $(21 \%, 17 / 80)$ and in $63(79 \%, 63 / 80)$ patients after 48 hours (between day 3 and day 8). In 58 patients $(73 \%, 58 / 81)$, the plastic surgeon performed the closure of the skin by the means of a flap. See Fig. 1 for an overview of surgical procedures performed on patients born with MMC at our center.

\section{Hydrocephalus}

Hydrocephalus was present in 78 patients (84\%), of whom 74 underwent VP shunt placement as initial treatment, 2 underwent ETV as primary treatment, and 2 patients were successfully treated conservatively. See Fig. 2 for a flowchart showing the management of hydrocephalus. Five $(7.1 \%)$ patients were treated within a week after closure of the MMC, 59 (84.3\%) between 1 week and 1 month after closure, and $6(8.6 \%)$ between 1 month and 1 year after closure of the MMC. Of the 2 patients who underwent antenatal repair, 1 needed shunt placement due to hydrocephalus.

Fifty-five of 76 (72\%) patients needed at least one revision during follow-up with a mean of 2.9 revisions (range 1-8 revisions). The main reasons were shunt malfunction in $65.5 \%$ and infection in $25.5 \%$ of cases. In 5 patients, an ETV was performed instead of a shunt revision (Table 2).

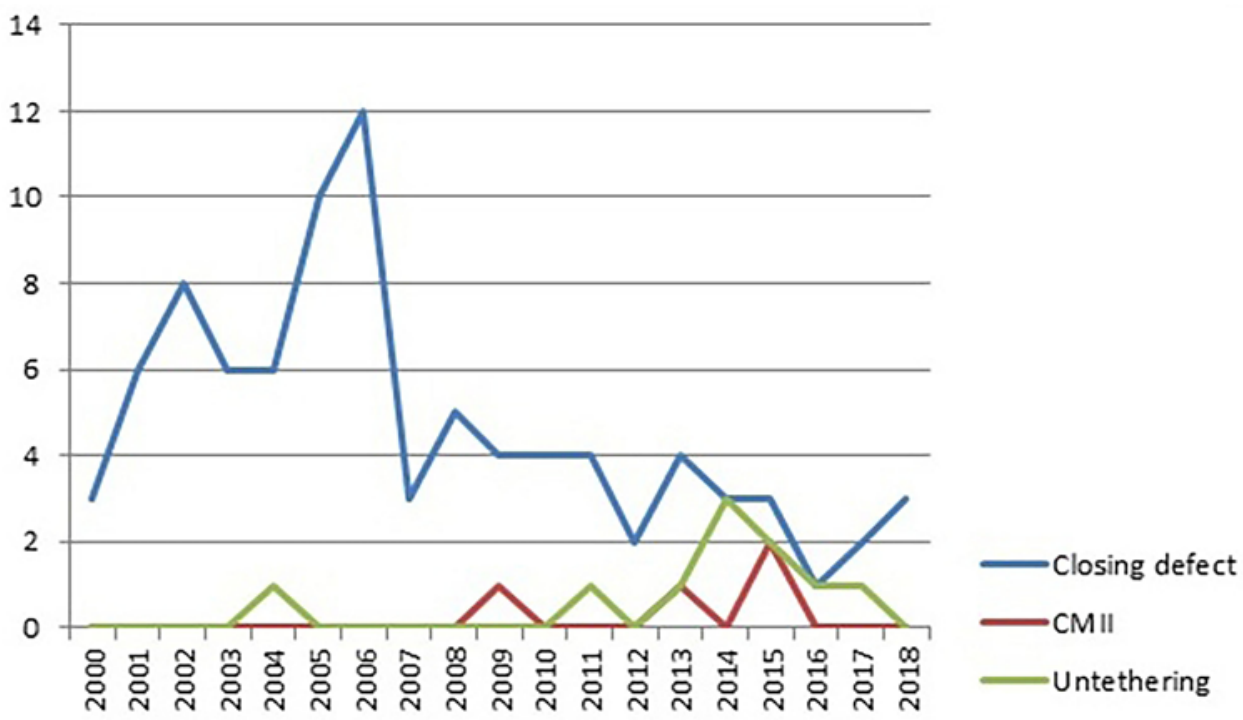

FIG. 1. An overview of the number of patients who underwent surgical procedures related to MMC throughout the years. 


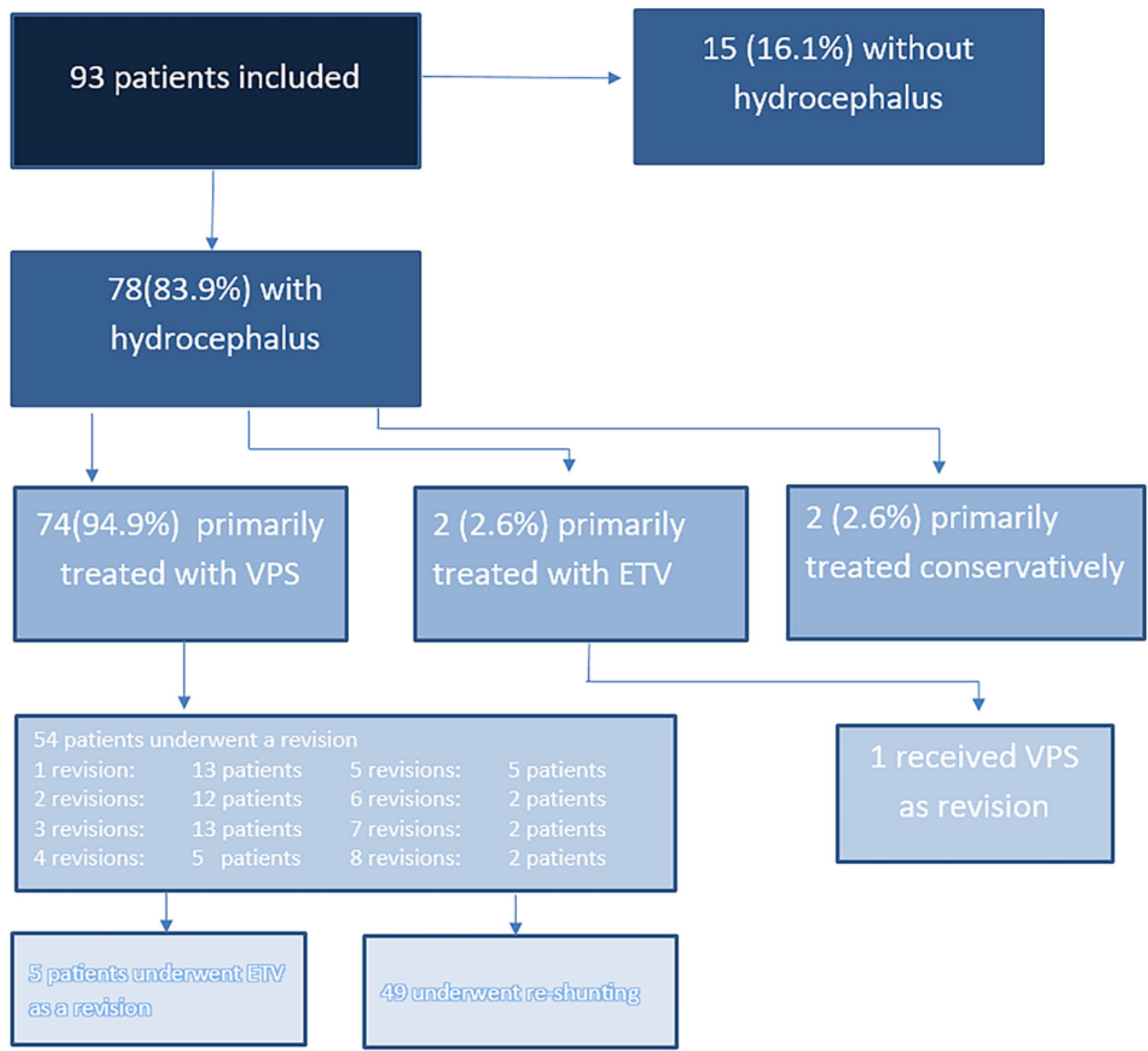

FIG. 2. Flowchart depicting the treatment of hydrocephalus among MMC patients. VPS = VP shunt.

\section{Hindbrain Herniation}

Radiological evidence of CMTII on MRI was present in 79 patients $(90 \%)$, which was clinically relevant in 5 patients. In 3 patients (4\%), posterior fossa decompression was indicated for bulbar symptoms in 2 patients and because of loss of motor function in the remaining patient (Table 3). Two patients improved after surgery; the remaining patient had to undergo reoperation with no clear clinical improvement.

\section{Tethering of the Spinal Cord}

Similar to CMTII, almost all patients showed a TSC on MRI. In 11 patients (12\%), an untethering procedure was deemed necessary. The mean age at surgery was 8 years (range 3-16 years). The indications for surgery were back and leg pain in 1 patient, progression of scoliosis in 2, bladder dysfunction in 2, and decline in lower-limb motor function in 4 patients.

Since 2009, surgery has been performed using intra- operative neuromonitoring (IONM), and in the majority of cases a widening nonresorbable dural patch was used.

\section{Long-Term Quality of Life \\ Cognition}

Thirty-two patients $(37 \%, 32 / 86)$ attended regular schools, whereas $54(63 \%, 54 / 86)$ go to special schools, and 4 patients did not reach school age at the time of this study. The presence of radiological hydrocephalus was significantly associated with following special education $(\mathrm{p}<0.015)$.

\section{Ability to Walk}

Table 4 shows the ability to walk according to the Hoffer scale ( $\mathrm{n}=86$; data were missing in 3 patients, and 4 patients were still under the age of walking at the time of the study; $18.6 \%$ of patients were able to walk independently at the last time of follow-up and $46.5 \%$ were nonambulators. 
TABLE 2. Management of hydrocephalus

\begin{tabular}{|c|c|}
\hline & No. of Patients (\%) \\
\hline \multicolumn{2}{|c|}{ Presence of hydrocephalus $(n=93)$} \\
\hline Yes & $78(83.9)$ \\
\hline No & $15(16.1)$ \\
\hline \multicolumn{2}{|c|}{ Primary treatment $w /$ a shunt $(n=82)$} \\
\hline Yes & $74(90.2)$ \\
\hline No & $8(9.8)$ \\
\hline \multicolumn{2}{|c|}{ Mean duration until op for hydrocephalus $(n=70)$} \\
\hline$<1$ wk & $5(7.1)$ \\
\hline$>1 \mathrm{wk}$ to $<1 \mathrm{mo}$ & $59(84.3)$ \\
\hline$>1 \mathrm{mo}$ to $<1 \mathrm{yr}$ & $6(8.6)$ \\
\hline \multicolumn{2}{|c|}{ Reop during follow-up $(n=78)$} \\
\hline Yes & $55(70.5)$ \\
\hline No & $23(29.5)$ \\
\hline \multicolumn{2}{|c|}{ Reasons for revision $(n=55)$} \\
\hline Overdrainage & $2(3.6)$ \\
\hline Infection & $14(25.5)$ \\
\hline Malfunction & $36(65.5)$ \\
\hline Check \& change & $2(3.6)$ \\
\hline CSF leakage & $1(1.8)$ \\
\hline \multicolumn{2}{|l|}{ Eventual reop } \\
\hline VP shunt & $50(90.9)$ \\
\hline ETV & $5(9.1)$ \\
\hline
\end{tabular}

\section{Urine Continence}

We defined social continence as having no involuntary loss of urine between the clean intermittent catheterizations (CICs). There are various definitions for social continence depending on the purpose of research, but, in general, this term refers to an acceptable situation for the patient without significant disturbance of daily activities.

Sixty-eight patients $(75 \%, 68 / 91)$ had social continence. Twenty-one patients $(23 \%, 21 / 91)$ reported some degree of involuntary loss of urine in between the CICs.

All patients started with CICs and anticholinergics shortly after birth. In total, 8 patients received a bladder augmentation with or without a continent catheterizable stoma. Nine patients received a continent catheterizable stoma alone. One patient needed a temporary vesicostomy at the age of 2 years in order to protect the upper urinary tract. None of the patients born in our hospital experienced a significant deterioration of renal function.

\section{Bowel Function}

Ten patients had undisturbed bowel emptying, whereas 4 patients reported some fecal incontinence. The vast majority of the patients (84\%) had severe difficulties in emptying their bowels properly (Table 4 ).

\section{Discussion}

In this study, we describe a contemporary cohort of infants who underwent postnatal repair for MMC. Hydrocephalus remains the main condition requiring surgical
TABLE 3. Management of hindbrain herniation

\begin{tabular}{|c|c|}
\hline & No. of Patients (\%) \\
\hline \multicolumn{2}{|l|}{ CMTII on imaging $(n=88)$} \\
\hline Yes & $79(89.8)$ \\
\hline No & $9(10.2)$ \\
\hline \multicolumn{2}{|c|}{ Clinical symptoms of CMTII $(n=74)$} \\
\hline Yes & $4(5.4)$ \\
\hline No & $70(94.6)$ \\
\hline \multicolumn{2}{|c|}{ Indication for decompression $(n=4)$} \\
\hline Central apnea & 3 \\
\hline Stridor & 0 \\
\hline Neck pain & 1 \\
\hline Syrinx & 0 \\
\hline Swallowing disorders & 0 \\
\hline \multicolumn{2}{|c|}{ Initial decompression for CMTII (n=2) } \\
\hline Bone only & 1 \\
\hline Duraplasty & 1 \\
\hline \multicolumn{2}{|c|}{ No. of reops for CMTII $(n=1)$} \\
\hline 1 & 1 \\
\hline 2 & 0 \\
\hline$>2$ & 0 \\
\hline Need for tracheostomy & 2 \\
\hline
\end{tabular}

intervention in the first month of life for the majority of cases. Despite radiological diagnoses of CMTII and TSC, these can most often be treated conservatively. Interestingly, the rate of untethering surgery in our series is relatively low. Motor function skills, cognitive capacity, and the occurrence of bladder/bowel dysfunction are comparable to other case series such as the National Spina Bifida Patient

TABLE 4. Quality of life at last follow-up

\begin{tabular}{cc}
\hline & No. of Patients $(\%)$ \\
\hline Ambulation according to Hoffer $(\mathrm{n}=86)$ & \\
\hline Nonambulators & $40(46.5)$ \\
\hline Nonfunctional ambulators & $7(8.1)$ \\
\hline Household ambulators & $9(10.5)$ \\
\hline Community ambulators & $14(16.3)$ \\
\hline Independent ambulators & $16(18.6)$ \\
\hline Level of education $(\mathrm{n}=90)$ & \\
\hline Special education & $54(60.0)$ \\
\hline Regular education & $32(35.6)$ \\
\hline Too young & $4(4.4)$ \\
\hline Bowel function $(\mathrm{n}=90)$ & $76(84.4)$ \\
\hline Constipation & $4(4.4)$ \\
\hline Incontinence & $10(11.8)$ \\
\hline Normal & \\
\hline Urinary continence $(\mathrm{n}=91)$ & $68(74.7)$ \\
\hline Yes & $23(25.3)$ \\
\hline No
\end{tabular}


Registry (NSBPR) consisting of almost 8000 patients (age range $0-89$ years). The NSBPR aims to identify variation between institutes and its impact on clinical outcomes, facilitate research, and improve health-related quality of life among patients with spina bifida. ${ }^{28}$

\section{Hydrocephalus}

Our rate of $84 \%$ is comparable to that of both the NSBPR and MOMS trial. Kim et al..$^{13,14}$ looked at shunting rates among NSBPR centers ${ }^{8}$ and included 4448 patients with MMC. Eighty percent of patients had undergone at least one procedure for hydrocephalus. Among the 23 centers, the shunt rate varied from $72 \%$ to $96 \%$. The shunt rate in the MOMS trial was $82 \%$ in the postnatal group and $40 \%$ in the prenatal group. ${ }^{1}$ Tulipan et al. showed similar outcomes for the entire MOMS trial population in 2015. ${ }^{30}$

Seventy-one percent of our patients needed at least 1 revision, which is a very significant number but comparable to that reported in the literature, with rates ranging between $64 \%$ and $95 \%$. We found a shunt infection rate of $25 \%$, which is rather high compared with that of Bowman et al. (10\%) but comparable to that of Tuli et al. (24\%)., 5 Overall, this demonstrates that hydrocephalus is a significant and very challenging condition in MMC patients, with a profound effect on cognitive function.

In recent years, the role of ETV as a treatment option for hydrocephalus has been reemerging. In a pediatric population of 501 patients with mixed etiologies of hydrocephalus (e.g., tumor, aqueductal stenosis) the success of ETV was $71 \% ;{ }^{17} 41.5 \%$ of the ETVs failed during followup, and $24 \%$ of these patients underwent re-ETV and $76 \%$ required shunting. Patients $0-6$ months old were more likely to have ETV failure, which is also the age category in which most patients in our series undergo a CSF-diverting procedure. Another study consisting of 18 pediatric patients with MMC treated with ETV or VP shunt showed a similar rate of ETV success (37.5\%). ${ }^{26}$ Because of the risk of infection as well as the high reoperation rate in VP shunting, we consider ETV the preferred approach whenever feasible; ETV also shows promising results in patients who underwent prenatal closure. ${ }^{6}$

The rate of shunt infection at our center may be deemed as relatively high (with 14 of the 74 shunts being infected). Throughout the years, multiple recommendations have been proposed to decrease the rate of shunt infections. ${ }^{7,15,21,27}$ Having a specific shunt protocol can help decrease infection rates, as can the use of antimicrobialimpregnated and -coated shunt catheters. Intraoperative irrigation with saline or the use of antimicrobial sutures for wound closure also show positive effects on shunt infection rates.

In a retrospective study of 127 patients with MMC, the concurrent placement of a shunt with the repair of the MMC defect, versus a delayed insertion of the shunt after repair, did not lead to any significant rates of shunt complications..$^{25}$

\section{CMTII}

At our institution, when patients with MMC present with complaints of hindbrain herniation, a thorough assessment including MRI and sleep and swallow studies is performed. If indeed clinically relevant CMTII is present, we first establish the functioning of the shunt. We only consider a surgical decompression if there is no doubt about shunt function and the Chiari complaints are substantial. The rate of decompression surgery for CMTII in our center (4\%) is rather low compared with that of $9.15 \%$ in the NSBPR.${ }^{13}$ Adzick et al. ${ }^{1}$ found a 5\% decompression surgery rate in the MOMS trial for the postnatal group and a $1 \%$ rate for the prenatal group at the 1 st year after birth. In our cohort, 2 patients underwent decompression surgery for CMTII before the age of 12 months (at 4 and 8 months). The third patient was 3.5 years old at surgery. It is well known that CMTII can become manifest at older ages, emphasizing that a long follow-up is needed to determine the incidence of CMTII decompression surgery.

Among the 23 NSBPR centers enrolling more than 10 patients, the rate of decompressions varied from $1.28 \%$ to $23.57 \%$. Reoperation was performed in $10.8 \%$ of the patients who underwent a CMTII decompression. In $2.7 \%$ of this group, even a second or third reoperation was needed. At our center, one patient underwent reoperation. Since only 3 patients underwent surgery for CMTII, this constitutes a 33\% reoperation rate. Due to these small numbers, a proper comparison is limited.

\section{TSC}

The percentage of cases that required surgical intervention for TSC in our series is relatively low. Similar cohort series, however, have reported a long-term risk of surgery for TSC of up to $32 \% .^{5}$ On the other hand, the oldest patient in our cohort was 18 years, and the majority are several years younger, which might in part explain our lower rate. Furthermore, the indication for TSC surgery at our institution is based on very stringent criteria; hence, this could also account for differences in surgery rates compared with other single-center series.

The treatment of clinically important TSC is challenging and often requires surgical interventions with not always successful outcomes. As such, an optimal closure technique at the initial surgery seems essential to prevent such long-term complications. With this in mind there is some concern about antenatal repairs. Despite clear benefits on motor skills and CMTII, the MOMS cohort also had a relatively higher need for TSC surgery in infants who underwent prenatal closure. Albeit not significantly different, in $8 \%$ of fetal surgery cases an untethering surgery was performed at the age of 12 months compared with only $1 \%$ in the postnatal group. This emphasizes the importance of long-term follow-up studies as are currently organized by the MOMS centers. On the other hand, the surgical technique to close the MMC during open fetal surgery is in principle similar to what is used in postnatal repair. Ongoing research on improvement of fetal surgery for MMC, especially of the fetoscopic technique, is therefore of the utmost importance. ${ }^{22}$

\section{Ability to Walk}

Of our patients, $19 \%$ were able to walk independently, which is comparable to the $21 \%$ in the postnatal group of the MOMS trial. It is less than half of the $42 \%$ of patients who were able to walk independently in the prena- 
tal MOMS trial group, showing the clear benefit of fetal MMC closure on this socially important factor.

\section{Cognition}

In our cohort only one-third of patients attended regular schools, whereas the majority needed special education. The radiological presence of hydrocephalus was the most important risk factor for cognitive developmental delay. This is similar to what has been published by various groups..$^{3,18}$ Our relatively high rate of shunt infection might also play a role in this. Interestingly, a more recent cohort series consisting of 108 cases from the MOMS trial did not confirm this association. They observed no difference in cognitive function between patients without hydrocephalus, shunt-treated hydrocephalus, or untreated hydrocephalus. ${ }^{10}$

Before the MOMS trial, Johnson et al. showed that shunt-treated MMC patients who underwent antenatal MMC closure had lower neurodevelopmental outcome scores at the age of 2 years. ${ }^{12}$ A systematic review by Inversetti et al. demonstrated no differences in the risk for neurodevelopmental impairment between antenatal- and postnatal-treated infants. ${ }^{11}$

Overall, the correlation between hydrocephalus and a higher need for special schools in our cohort of MMC patients represents only part of the literature and may represent the effects of shunt placement and high occurrence of revision surgery.

\section{Strengths and Limitations}

The main strength of this study is related to the unique standardized multidisciplinary follow-up clinic at our institution, which results in a low lost-to-follow-up rate. This provides a wealth of information about contemporary outcomes of infants with MMC. Our study is limited by its retrospective design and the inevitable loss of data.

\section{Conclusions}

This study provides an overview of current outcomes for infants born with an MMC managed at our center. The overall outcomes are similar to those reported in the literature. However, we did observe a relatively low incidence of surgery for TSC. This study will serve as a historical cohort for comparison with future fetal surgery cases operated on at our center in the coming years. Hydrocephalus is highly prevalent in postnatally treated MMC patients, as is the revision rate for VP shunts, in which infection is a major reason for revision. In our study as in much of the literature, hydrocephalus is significantly correlated with a low cognitive function. Fetal surgery for MMC has been shown to halve the need for shunt treatment in a select group of pregnancies, and this constitutes a major indication for our center to undergo the transition to a fetal surgery center. Since shunt malfunction and shunt infection are frequently seen in shunt-treated MMC patients, we strongly promote ETV to be considered in case the need for a shunt revision is anticipated. The fetal benefits of open fetal surgery for MMC are well established in a select group of MMC pregnancies, yet it is well known and also illustrated by our series that MMC-related complications such as clinically relevant CMTII and especially TSC often occur years after closure of the MMC. Therefore, multicenter, long-term clinical data, especially regarding TSC in antenatally operated MMC patients compared with postnatally operated MMC patients, are eagerly awaited; an anticipated higher rate may stimulate ongoing research on further improvement of fetal closure techniques.

\section{References}

1. Adzick NS, Thom EA, Spong CY, Brock JW III, Burrows PK, Johnson MP, et al: A randomized trial of prenatal versus postnatal repair of myelomeningocele. N Engl J Med 364:993-1004, 2011

2. Akbari SH, Limbrick DD Jr, Kim DH, Narayan P, Leonard JR, Smyth MD, et al: Surgical management of symptomatic Chiari II malformation in infants and children. Childs Nerv Syst 29:1143-1154, 2013

3. Alimi Y, Iwanaga J, Oskouian RJ, Loukas M, Tubbs RS: Intelligence quotient in patients with myelomeningocele: a review. Cureus 10:e3137, 2018

4. Boulet SL, Yang Q, Mai C, Kirby RS, Collins JS, Robbins $\mathrm{JM}$, et al: Trends in the postfortification prevalence of spina bifida and anencephaly in the United States. Birth Defects Res A Clin Mol Teratol 82:527-532, 2008

5. Bowman RM, McLone DG, Grant JA, Tomita T, Ito JA: Spina bifida outcome: a 25 -year prospective. Pediatr Neurosurg 34:114-120, 2001

6. Elbabaa SK, Gildehaus AM, Pierson MJ, Albers JA, Vlastos EJ: First 60 fetal in-utero myelomeningocele repairs at Saint Louis Fetal Care Institute in the post-MOMS trial era: hydrocephalus treatment outcomes (endoscopic third ventriculostomy versus ventriculo-peritoneal shunt). Childs Nerv Syst 33:1157-1168, 2017

7. Hayashi T, Shirane R, Yokosawa M, Kimiwada T, Tominaga $\mathrm{T}$ : Efficacy of intraoperative irrigation with saline for preventing shunt infection. J Neurosurg Pediatr 6:273-276, 2010

8. Hoffer MM, Feiwell E, Perry R, Perry J, Bonnett C: Functional ambulation in patients with myelomeningocele. J Bone Joint Surg Am 55:137-148, 1973

9. Honein MA, Paulozzi LJ, Mathews TJ, Erickson JD, Wong LY: Impact of folic acid fortification of the US food supply on the occurrence of neural tube defects. JAMA 285:29812986, 2001

10. Houtrow AJ, Burrows PK, Thom EA: Comparing neurodevelopmental outcomes at 30 months by presence of hydrocephalus and shunt status among children enrolled in the MOMS trial. J Pediatr Rehabil Med 11:227-235, 2018

11. Inversetti A, Van der Veeken L, Thompson D, Jansen K, Van Calenbergh F, Joyeux L, et al: Neurodevelopmental outcome of children with spina bifida aperta repaired prenatally vs postnatally: systematic review and meta-analysis. Ultrasound Obstet Gynecol 53:293-301, 2019

12. Johnson MP, Gerdes M, Rintoul N, Pasquariello P, Melchionni J, Sutton LN, et al: Maternal-fetal surgery for myelomeningocele: neurodevelopmental outcomes at 2 years of age. Am J Obstet Gynecol 194:1145-1152, 2006

13. Kim I, Hopson B, Aban I, Rizk EB, Dias MS, Bowman R, et al: Decompression for Chiari malformation type II in individuals with myelomeningocele in the National Spina Bifida Patient Registry. J Neurosurg Pediatr 22:652-658, 2018

14. Kim I, Hopson B, Aban I, Rizk EB, Dias MS, Bowman R, et al: Treated hydrocephalus in individuals with myelomeningocele in the National Spina Bifida Patient Registry. J Neurosurg Pediatr 22:646-651, 2018

15. Konstantelias AA, Vardakas KZ, Polyzos KA, Tansarli GS, Falagas ME: Antimicrobial-impregnated and -coated shunt 
catheters for prevention of infections in patients with hydrocephalus: a systematic review and meta-analysis. J Neurosurg 122:1096-1112, 2015

16. Kshettry VR, Kelly ML, Rosenbaum BP, Seicean A, Hwang L, Weil RJ: Myelomeningocele: surgical trends and predictors of outcome in the United States, 1988-2010. J Neurosurg Pediatr 13:666-678, 2014

17. Lam S, Harris D, Rocque BG, Ham SA: Pediatric endoscopic third ventriculostomy: a population-based study. J Neurosurg Pediatr 14:455-464, 2014

18. Lindquist B, Uvebrant P, Rehn E, Carlsson G: Cognitive functions in children with myelomeningocele without hydrocephalus. Childs Nerv Syst 25:969-975, 2009

19. Mehta VA, Bettegowda C, Ahmadi SA, Berenberg P, Thomale UW, Haberl EJ, et al: Spinal cord tethering following myelomeningocele repair. J Neurosurg Pediatr 6:498-505, 2010

20. Messing-Jünger M, Röhrig A: Primary and secondary management of the Chiari II malformation in children with myelomeningocele. Childs Nerv Syst 29:1553-1562, 2013

21. Omrani O, O'Connor J, Hartley J, James G: Effect of introduction of a standardised peri-operative protocol on CSF shunt infection rate: a single-centre cohort study of 809 procedures. Childs Nerv Syst 34:2407-2414, 2018

22. Oria M, Tatu RR, Lin CY, Peiro JL: In vivo evaluation of novel PLA/PCL polymeric patch in rats for potential spina bifida coverage. J Surg Res 242:62-69, 2019

23. Park TS, Hoffman HJ, Hendrick EB, Humphreys RP: Experience with surgical decompression of the Arnold-Chiari malformation in young infants with myelomeningocele. Neurosurgery 13:147-152, 1983

24. Pollack IF, Pang D, Albright AL, Krieger D: Outcome following hindbrain decompression of symptomatic Chiari malformations in children previously treated with myelomeningocele closure and shunts. J Neurosurg 77:881-888, 1992

25. Radmanesh F, Nejat F, El Khashab M, Ghodsi SM, Ardebili HE: Shunt complications in children with myelomeningocele: effect of timing of shunt placement. Clinical article. J Neurosurg Pediatr 3:516-520, 2009

26. Rei J, Pereira J, Reis C, Salvador S, Vaz R: Endoscopic Third ventriculostomy for the treatment of hydrocephalus in a pediatric population with myelomeningocele. World Neurosurg 105:163-169, 2017
27. Rozzelle CJ, Leonardo J, Li V: Antimicrobial suture wound closure for cerebrospinal fluid shunt surgery: a prospective, double-blinded, randomized controlled trial. J Neurosurg Pediatr 2:111-117, 2008

28. Thibadeau J: The National Spina Bifida Patient Registry: past, present, and future. J Pediatr Rehabil Med 10:205210, 2017

29. Tuli S, Drake J, Lamberti-Pasculli M: Long-term outcome of hydrocephalus management in myelomeningoceles. Childs Nerv Syst 19:286-291, 2003

30. Tulipan N, Wellons JC III, Thom EA, Gupta N, Sutton LN, Burrows PK, et al: Prenatal surgery for myelomeningocele and the need for cerebrospinal fluid shunt placement. J Neurosurg Pediatr 16:613-620, 2015

31. Viswanathan M, Treiman KA, Kish-Doto J, Middleton JC, Coker-Schwimmer EJ, Nicholson WK: Folic acid supplementation for the prevention of neural tube defects: an updated evidence report and systematic review for the US Preventive Services Task Force. JAMA 317:190-203, 2017

\section{Disclosures}

The authors report no conflict of interest concerning the materials or methods used in this study or the findings specified in this paper.

\section{Author Contributions}

Conception and design: Spoor, Gadjradj, de Jong. Acquisition of data: Spoor, Gadjradj. Analysis and interpretation of data: Spoor, Gadjradj, Eggink, Scheepe, de Laat, van Veelen. Drafting the article: Spoor, Gadjradj. Critically revising the article: Gadjradj, Eggink, DeKoninck, Lutters, Scheepe, van Meeteren, de Laat, van Veelen, de Jong. Reviewed submitted version of manuscript: all authors. Approved the final version of the manuscript on behalf of all authors: Spoor. Statistical analysis: Spoor. Administrative/ technical/material support: Gadjradj.

\section{Correspondence}

Jochem K. H. Spoor: Erasmus MC University Medical Center Rotterdam, The Netherlands. j.spoor@erasmusmc.nl. 